\title{
Differences between Newborn and Adult Mice in Their Response to Immune Thrombocytopenia
}

\author{
Zhongbo Hu $^{a}$ William B. Slayton ${ }^{a}$ Lisa M. Rimsza ${ }^{b}$ Matthew Bailey ${ }^{a, c}$ \\ Hannes Sallmon ${ }^{c, d}$ Martha C. Sola-Visnera,c \\ ${ }^{a}$ Department of Pediatrics, University of Florida, Gainesville, Fla., b Department of Pathology, University of Arizona, \\ Tucson, Ariz., 'Division of Newborn Medicine, Children's Hospital Boston and Harvard Medical School, \\ Boston, Mass., USA; ${ }^{\mathrm{d}}$ Department of Neonatology, Charité - Universitätsmedizin Berlin, Berlin, Germany
}

Key Words

Megakaryocyte $\cdot$ Thrombocytopenia

\begin{abstract}
Background: Sick neonates frequently develop severe thrombocytopenia. Objective and Methods: In order to test the ability of fetal mice to increase their megakaryocyte size and ploidy in response to thrombocytopenia, we injected an antiplatelet antibody (MWReg30) into pregnant mice daily for 7 days, and into nonpregnant adult mice to serve as controls. After that time, platelet counts were obtained and megakaryocytes in the bone marrow, liver, and spleen were stained with anti-von Willebrand factor antibody, individually measured, and quantified. Results: Our study demonstrated that megakaryocytopoiesis in newborn mice shares many features of human fetal/neonatal megakaryocytopoiesis, including the small size of megakaryocytes. In response to thrombocytopenia, adult mice increased megakaryocyte volume and concentration, primarily in the spleen. Newborn mice, in contrast, increased the megakaryocyte concentration in the spleen, but exhibited no increase in megakaryocyte volume in any of the organs studied. In fact, the megakaryocyte mass was significantly lower in the bone marrow of thrombocytopenic neonates than in age-matched controls. Conclusions: We concluded that fetuses have a limited
\end{abstract}

ability to increase their megakaryocyte mass in response to consumptive thrombocytopenia, compared to adult mice. These observations provide further evidence for the existence of biological differences between fetal/neonatal and adult megakaryocytopoiesis. Copyright $\odot 2010$ S. Karger AG, Basel

\section{Introduction}

Thrombocytopenia is a common hematological problem among sick neonates, affecting $22-30 \%$ of all infants admitted to neonatal intensive care units $[1,2]$. Despite the high prevalence of neonatal thrombocytopenia, our understanding of the mechanisms underlying most cases has been significantly hampered by a number of factors, including the limited availability of bone marrow specimens from living preterm and term neonates, the relative rarity and fragility of megakaryocytes in the fetal marrow, and the lack of animal models.

Several studies, most of them evaluating cultured megakaryocytes in vitro, have reported significant differences between neonatal and adult megakaryocytopoiesis. It has recently been suggested that these differences may predispose sick neonates to develop severe and prolonged thrombocytopenia. Specifically, megakaryocytes

\section{KARGER}

(C) 2010 S. Karger AG, Basel

Fax +41613061234 E-Mail karger@karger.ch www.karger.com
Accessible online at: www.karger.com/neo
Martha C. Sola-Visner, MD

Division of Newborn Medicine, Children's Hospital Boston

300 Longwood Avenue, Enders Research Building, Rm. 961

Boston, MA 02115 (USA), Tel. +1 617919 4845, Fax +1 6177300260

E-Mail Martha.Sola-Visner@childrens.harvard.edu 
isolated from fetal liver, fetal bone marrow, or cord blood are significantly smaller and have lower ploidy levels than those found in adult bone marrow [3-6]. Since larger megakaryocytes generate more platelets than smaller megakaryocytes [7], it has been assumed that neonatal megakaryocytes produce fewer platelets than adult megakaryocytes. Furthermore, it has been suggested that the normal platelet counts found in healthy fetuses and neonates are maintained by the increased proliferative rate of fetal megakaryocyte progenitors $[8,9]$.

In adults, increased platelet consumption triggers a compensatory response in megakaryocytopoiesis, characterized by an increase in megakaryocyte size and ploidy, followed by an increase in megakaryocyte number. These changes, thought to be mostly mediated by elevated concentrations of thrombopoietin (Tpo), ultimately result in a 2 - to 8 -fold increase in total megakaryocyte mass and a corresponding increase in platelet production $[10,11]$. It is unknown, however, whether neonates are capable of similarly increasing their megakaryocyte mass in response to platelet consumption, or whether the small size and low ploidy of their megakaryocytes represent a developmental limitation in their ability to adequately increase platelet production. To answer this question, we recently evaluated megakaryocyte size in bone marrow specimens from human neonates with and without thrombocytopenia, and found no differences between thrombocytopenic and nonthrombocytopenic neonates. In contrast, a group of adult patients with immune thrombocytopenic purpura exhibited a significant increase in megakaryocyte size compared to their nonthrombocytopenic counterparts [12]. However, the causes of thrombocytopenia were highly diverse among the neonatal subjects, and it remained unclear whether the differences between neonates and adults reflected a true developmental limitation, or whether they were rather explained by the different disease processes underlying neonatal and adult thrombocytopenia.

To answer this question, we developed a mouse model of fetal/neonatal immune thrombocytopenic purpura. Among the several methods that have been used to generate immune thrombocytopenic purpura in adult mice [13-15], one of the most widely used induces thrombocytopenia by injecting a platelet-specific anti-CD41a antibody (MWReg30). Since MWReg30 is an IgG1 antibody, and IgG1 immunoglobulins are known to be particularly effective in crossing the placenta, we induced fetal immune thrombocytopenia by injecting this antibody into pregnant mice. We then evaluated platelet counts, megakaryocyte size, and megakaryocyte number in the affect- ed newborn pups, as well as in adult mice with similar degrees of thrombocytopenia induced by the same antibody. Concordant with our observations in humans, these studies demonstrated that fetal mice do not increase their megakaryocyte volume in response to increased platelet demand.

\section{Materials and Methods}

\section{Animals}

C57BL/6 mice weighing 20-25 g were purchased from Harlan (Indianapolis, Ind., USA), and timed matings were performed as needed. These studies were approved by the University of Florida Institutional Animal Care and Use Committee.

\section{Antibodies}

Rat anti-mouse platelet monoclonal antibody (MWReg30, IgG1) was obtained from BD Biosciences (San Diego, Calif., USA). Polyclonal rabbit anti-human von Willebrand Factor (vWF; Code No. A 0082) was purchased from DakoCytomation (Denmark). For immunohistochemistry, we used the VECTASTAIN Elite ABC Kit (Vector, Burlingame, Calif., USA).

\section{Induction of Thrombocytopenia}

Fetal thrombocytopenia was induced by injecting MWReg30 antibody (BD Biosciences) into pregnant mice daily, starting on gestation day E12.5 until the time of delivery (E19.5 for most litters). After anesthesia with isofluorane, pregnant mice underwent tail vein injections of MWReg30 ( $0.5 \mu \mathrm{g} / \mathrm{g}$ body weight, to account for the high volume of distribution of pregnant mice) diluted in $100 \mu \mathrm{l}$ PBS plus $1.5 \mathrm{mg} / \mathrm{ml}$ albumin. To generate adult thrombocytopenic mice, 2-month-old mice were subcutaneously injected with MWReg30 (0.18 $\mu \mathrm{g} / \mathrm{g})$ daily for 7 days. Controls were generated by injecting pregnant and nonpregnant mice with $100 \mu \mathrm{l}$ PBS $+1.5 \mathrm{mg} / \mathrm{ml}$ albumin (carrier).

\section{Analysis of Platelet Counts}

Following 7 days of treatment with MWReg30, $50 \mu$ l of blood were obtained from thrombocytopenic and control adult mice by retroorbital bleeding, using heparinized Natelson blood-collecting tubes (Fisher Scientific, Pittsburgh, Pa., USA). Anesthetized newborn pups underwent intracardiac puncture the day after delivery. Approximately $20 \mu \mathrm{l}$ of blood were drawn from each pup using Monoject 29G $\times 0.5-\mathrm{ml}$ syringes (Tyco Healthcare Group LP, Mansfield, Mass., USA) coated with $20 \mu$ l of anticoagulant citrate dextrose solution (Baxter Healthcorp, Deerfield, Ill., USA). Complete blood counts were obtained on an automated cell counter (Becton-Dickinson AcT10-Diff with veterinary card).

\section{Histology and Immunohistochemistry}

Bones, spleens and livers from thrombocytopenic and control adult and newborn pups were fixed overnight in $4 \%$ paraformaldehyde. The tissues were then embedded in paraffin, cut into 5$\mu \mathrm{m}$ sections, and attached to Bond-rite slides. Slides were treated with $3 \%$ hydrogen peroxide for $10 \mathrm{~min}$ to quench endogenous peroxidase activity, and incubated with $10 \%$ normal horse serum to block nonspecific antibody binding. Endogenous biotin binding 
was blocked using an avidin/biotin blocking kit. A rabbit anti-human vWF antibody known to crossreact with murine vWF (Code No. A 0082, DakoCytomation, Denmark) was used as the primary antibody to immunohistochemically stain megakaryocytes. A biotinylated horse anti-rabbit antibody was used as the secondary antibody, and color development was achieved with diaminobenzidinesubstrate following the Vector Elite ABC kit protocols (Vector).

\section{Evaluation of Megakaryocytopoiesis}

Megakaryocytes, identified by immunohistochemical staining with vWF in conjunction with morphological features, were quantified in all organs using an eyepiece reticle $\left(250 \mu \mathrm{m}^{2}\right.$ per 9 small squares at 400×; Klarmann Rulings Inc., Litchfield, N.H., USA), as we have previously described [12]. The megakaryocyte concentration was then expressed as megakaryocytes per 250 $\mu \mathrm{m}^{2}$ of liver, spleen, or bone marrow. To evaluate megakaryocyte size, the $\mathrm{X}$ and $\mathrm{Y}$ axis diameters of either 50 or all megakaryocytes in each slide (whichever came first) were measured using an eyepiece microruler $(100-\mu \mathrm{m}$ ruler at $400 \times$, Klarmann Rulings Inc.). The mean diameter of each megakaryocyte was derived from its $\mathrm{X}$ and $\mathrm{Y}$ axis measurements. Assuming a spheroidal shape of megakaryocytes, we then calculated the mean megakaryocyte volume from the diameter measurements, using the following formula: volume $=\pi$ (diameter) $3 / 6$. The product of the megakaryocyte concentration and mean megakaryocyte volume of each slide was calculated to determine a mathematical estimate of the organ-specific megakaryocyte mass, as previously described $[10,11]$.

\section{Megakaryocyte Colony Assays}

To assess megakaryocyte progenitor numbers in this model of immune thrombocytopenia, murine megakaryocyte colony assays were performed using MegaCult-C culture media (StemCell Technologies, Vancouver, B.C., Canada). Briefly, adult bone marrow cells were flushed from tibiae and femora, and newborn liver cells were disaggregated and brought to a single cell suspension by passing the tissue through serially smaller needles. Nucleated cells were then separated by Ficoll-Paque centrifugation and cultured at a concentration of $1 \times 10^{5}$ nucleated cells per chamber slide in Iscove's Modified Dulbecco's Medium supplemented with $1 \% \mathrm{BSA}, 10 \mu \mathrm{g} / \mathrm{ml}$ recombinant human insulin, $200 \mu \mathrm{g} / \mathrm{ml} \mathrm{hu}-$ man transferrin, $2 \mathrm{mM}$ L-glutamine, $10^{-4}$ M 2-mercaptoethanol, $50 \mathrm{ng} / \mathrm{ml}$ recombinant human thrombopoietin, and $10 \mathrm{ng} / \mathrm{ml} \mathrm{re-}$ combinant murine IL-3. After 8 days of culture, the slides were dehydrated, fixed with acetone, and evaluated using acetylcholinesterase staining. Colonies were scored using an Olympus BX40 microscope under a $10 \times$ objective. CFU-megakaryocytes were defined as pure megakaryocytic colonies containing more than 50 megakaryocytes per colony, mixed megakaryocytic colonies contained nonmegakaryocytic and megakaryocytic cells in the same cluster, and granulocyte/macrophage colonies ( $>30$ cells) did not contain megakaryocytes.

\section{Statistical Analysis}

Results were expressed as mean \pm SEM, except when indicated. The significance of the differences between the two groups was investigated using Student's t tests. Level of significance was set at $\mathrm{p}<0.05$.

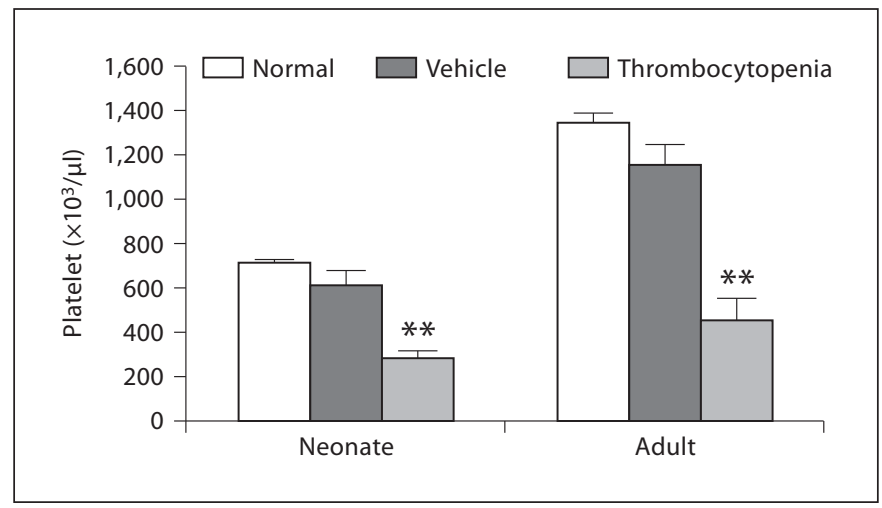

Fig. 1. Platelet counts in newborn and adult mice. One-day-old healthy neonates had significantly lower platelet counts than healthy adult mice. Control mice received daily injections of the antibody vehicle and had platelet counts similar to those of untreated age-matched animals. Mice rendered thrombocytopenic by daily injections of MWReg30 had platelet counts that were significantly lower than age-matched placebo controls. Data are shown as means \pm SEM. ${ }^{* *} \mathrm{p}<0.001$ vs. placebo control.

\section{Results}

\section{Platelets and Megakaryocytes in Normal Newborn and Adult Mice}

First, we sought to establish the normal platelet count ranges for newborn and adult $\mathrm{C} 57 \mathrm{BL} / 6$ mice. Platelet counts were significantly lower in healthy 1-day-old mice than in 2-month-old mice (mean \pm SD: $710 \pm 148 \times$ $10^{6} / \mathrm{ml}$ vs. $1,342 \pm 186 \times 10^{6} / \mathrm{ml} ; \mathrm{p}<0.001$ ) (fig. 1 ). Thrombocytopenia was therefore defined as a platelet count less than two standard deviations below the ageappropriate mean $\left(<415 \times 10^{6} / \mathrm{ml}\right.$ in newborn pups and $<970 \times 10^{6} / \mathrm{ml}$ in adult mice).

To determine whether C57BL/6 mice exhibited developmental differences in megakaryocytopoiesis comparable to those described in humans (and were therefore an adequate model for this study), we then evaluated megakaryocyte concentration and size in the bone marrow, liver, and spleen of normal newborn and adult mice [16]. As shown in table 1, the liver was the main site of megakaryocytopoiesis in the healthy newborn mouse (similarly to an early second-trimester human fetus [17, 18]), while the bone marrow had the highest megakaryocyte concentration in the adult mouse. Indeed, the bones in the newborn mice were largely cartilaginous, and the marrow space was not yet completely formed. Megakaryocytes were present in the spleen of newborn and adult mice, but in lower concentrations than in the liver or 
Fig. 2. Photomicrograph of megakaryocytes expressing vWF (original magnification $\times 400$ ) in the liver of control newborn pups (a), thrombocytopenic newborn pups (b), bone marrow from control adults (c), and bone marrow from thrombocytopenic adults (d). The difference in size between neonatal and adult megakaryocytes is clearly evident.

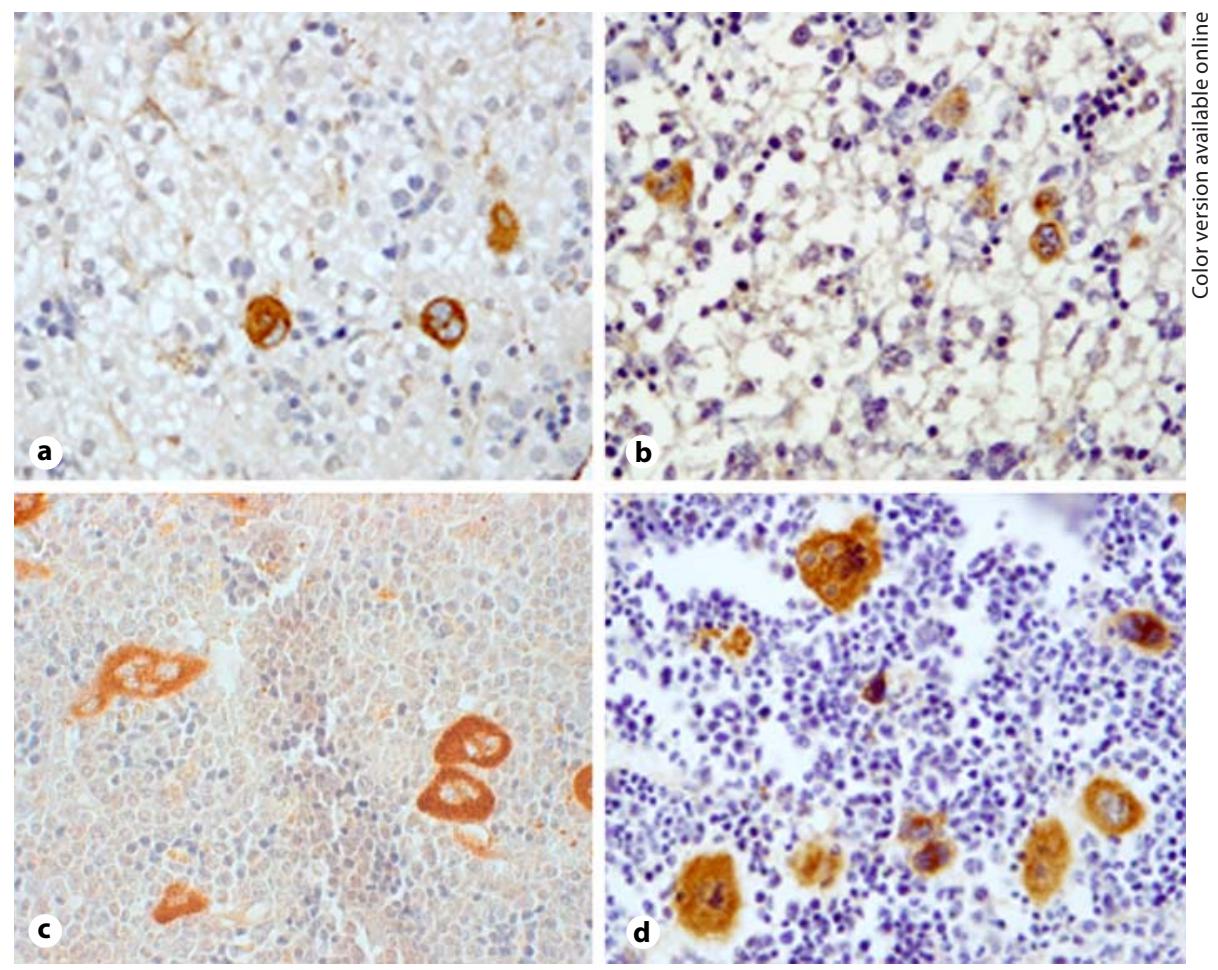

Table 1. Megakaryocyte (Mk) concentration, diameter and volume in normal neonatal and adult mice

\begin{tabular}{|c|c|c|c|c|c|c|}
\hline & \multicolumn{3}{|c|}{ Newborn mice $(\mathrm{n}=34)$} & \multicolumn{3}{|c|}{ Adult mice $(\mathrm{n}=22)$} \\
\hline & $\begin{array}{l}\text { concentration } \\
\mathrm{Mk} / 250 \mu \mathrm{m}^{2}\end{array}$ & $\begin{array}{l}\text { diameter } \\
\mu \mathrm{m}\end{array}$ & volume & $\begin{array}{l}\text { concentration } \\
\mathrm{Mk} / 250 \mu \mathrm{m}^{2}\end{array}$ & $\begin{array}{l}\text { diameter } \\
\mu \mathrm{m}\end{array}$ & volume \\
\hline Bone marrow & $0.33 \pm 0.04(\mathrm{n}=10)$ & $14.06 \pm 1.08$ & $1,817.9 \pm 410.9$ & $5.27 \pm 0.34$ & $20.13 \pm 0.32$ & $4,403.9 \pm 199.7$ \\
\hline Liver & $1.78 \pm 0.12$ & $16.04 \pm 0.14$ & $2,167.9 \pm 57.7$ & no Mks & & \\
\hline Spleen & $0.84 \pm 0.16$ & $15.21 \pm 0.45$ & $1,964.9 \pm 174.9$ & $0.70 \pm 0.19$ & $20.76 \pm 0.32$ & $4,865.4 \pm 154.3$ \\
\hline
\end{tabular}

bone marrow, respectively. No megakaryocytes were identified in the adult liver. As in humans, megakaryocytes were significantly smaller in newborn than in adult mice ( $<<0.001)$ (fig. 2).

\section{Determining the Effects of the Anti-Platelet Antibody} on Platelet Counts and Megakaryocytopoiesis

After administration of antiplatelet antibody for 7 consecutive days, the mean platelet counts in newborn and adult mice were $30-40 \%$ of the normal means for age $\left(287 \pm 27 \times 10^{6} / \mathrm{ml}\right.$ for neonates, $\mathrm{n}=12 ; 452 \pm 98 \times$ $10^{6} / \mathrm{ml}$ for adults; $\mathrm{n}=8$ ) (fig. 1 ). However, the responses to thrombocytopenia varied depending on the develop- mental stage (newborn vs. adult) and the hematopoietic organ studied. Specifically, when thrombocytopenic newborn mice were compared to age-matched controls, the megakaryocyte concentration did not change significantly in the neonatal liver $(1.6 \pm 0.1$ vs. $1.9 \pm 0.1, \mathrm{p}=$ $0.21)$, but decreased in the bone marrow $(0.2 \pm 0.04$ vs. $0.5 \pm 0.1, \mathrm{p}=0.02)$ and increased in the spleen $(0.69 \pm$ 0.10 vs. $0.37 \pm 0.08, p=0.04$ ) (fig. 3a). Adult thrombocytopenic mice also had a higher megakaryocyte concentration in the spleen compared to controls $(1.04 \pm 0.15$ vs. $0.68 \pm 0.11, \mathrm{p}=0.01)$, but exhibited no significant change in the bone marrow $(8.74 \pm 0.59$ vs. $8.33 \pm 0.70$, $\mathrm{p}=0.67)$ (fig. 3d). 


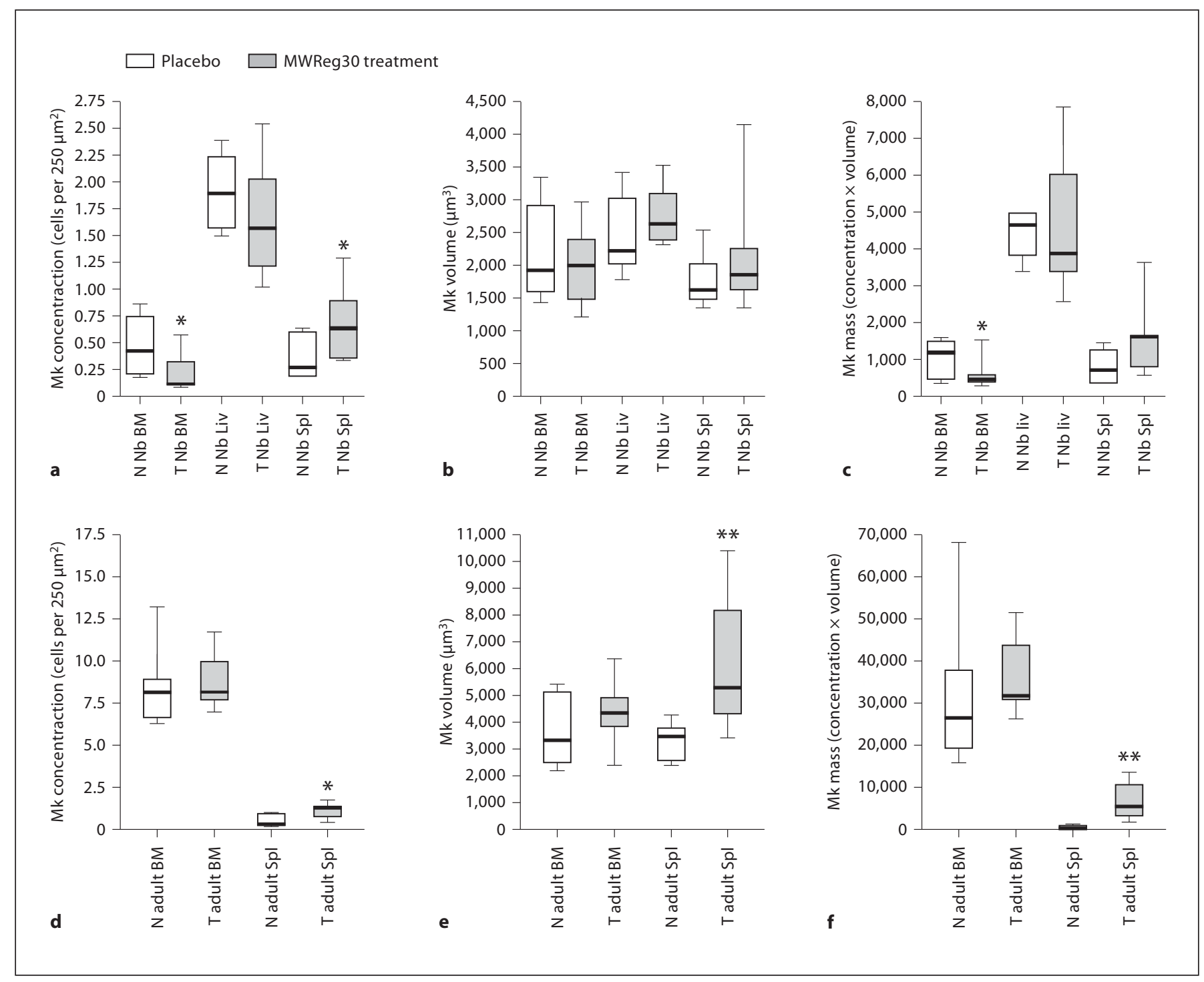

Fig. 3. Box-plots displaying the megakaryocyte (Mk) concentration, size and mass in the bone marrow (BM), liver (Liv) and spleen $(\mathrm{Spl})$ of neonates $(\mathbf{a}-\mathbf{c})$, and in the bone marrow and spleen of adult mice (d-f). The boxplot margins represent the 25 th-75th percentiles, the whiskers represent the ranges, and the line, the median. $\mathrm{N}=$ Normal; $\mathrm{T}=$ thrombocytopenic. ${ }^{*} \mathrm{p}<0.05$ and ${ }^{* *} \mathrm{p}<0.01$ versus age-matched controls.

In regard to megakaryocyte size, thrombocytopenic newborn mice did not increase their megakaryocyte volume compared to controls in any of the hematopoietic organs analyzed, including the liver $(2,783.4 \pm 123.8$ vs. $2,521.2 \pm 173.2, \mathrm{p}=0.23)$, spleen $(2,122.4 \pm 233.6$ vs. $1,788.7 \pm 110.3, \mathrm{p}=0.21)$ and bone marrow $(2,011.4 \pm$ 163.4 vs. $2,156.7 \pm 278.3, p=0.64$ ) (fig. $3 b$ ). In contrast, thrombocytopenic adult mice had significantly larger megakaryocytes than controls in the spleen $(6,071.6 \pm$ 915.6 vs. $3,131.0 \pm 226.2, \mathrm{p}<0.01)$ although not in the bone marrow $(4,250.4 \pm 417.1$ vs. $3,657.7 \pm 447.4, \mathrm{p}=$ $0.35)$ (fig. 3e).

To mathematically estimate the combined effect of megakaryocyte number and size on the megakaryocyte mass, we then multiplied the mean megakaryocyte concentration by the mean volume in each organ. This analysis revealed a substantial reduction in the bone marrow megakaryocyte mass in thrombocytopenic newborn mice compared to controls $(473.0 \pm 99.0$ vs. $1,009.9 \pm$ 199.7, $\mathrm{p}=0.02$ ), and no significant change in the liver 
$(4,595.1 \pm 494.9$ vs. $4,489.1 \pm 261.8, \mathrm{p}=0.89)$ or the spleen $(1,505.9 \pm 282.5$ vs. $721.7 \pm 173.9, \mathrm{p}=0.07)$ although the latter one exhibited a trend (fig. 3c). Thrombocytopenic adult mice, in contrast, increased their megakaryocyte mass by approximately 4 -fold in the spleen $(6,727.1 \pm 1,603.5$ vs. $1,603.7 \pm 231.1, \mathrm{p}<0.01)$, and exhibited no significant change in the bone marrow $(36,128.1 \pm 3,145.1$ vs. $30,915.8 \pm 5,406.8, \mathrm{p}=0.43)$ (fig. 3f).

\section{Effect of MWReg30 on Megakaryocyte Progenitors}

We then sought to evaluate megakaryocyte progenitor number in mice with MWReg30-induced thrombocytopenia, using megakaryocyte progenitor assays $(n=6$ per group). As shown in figure 4, neonatal liver cells from nonthrombocytopenic mice gave rise to significantly more megakaryocyte colonies than adult bone marrow cells $(181.1 \pm 32.8$ vs. $26.5 \pm 4.3$, p < 0.001). Thrombocytopenic mice had colony counts similar to those of their nonthrombocytopenic age-matched controls (131.1 \pm 30.1 vs. $181.1 \pm 32.8$ and $36.9 \pm 11.3$ vs. $26.5 \pm 4.3$ for neonates and adults, respectively).

\section{Discussion}

In the present study, we compared the responses of fetal and adult C57BL/6 mice to thrombocytopenia induced by the administration of an antiplatelet antibody. The main objective of the study was to determine whether fetal mice respond to immune thrombocytopenia in a manner similar to adult mice, or whether fetuses/neonates exhibit developmental differences in response to increased platelet demand. Based on our previous observations in thrombocytopenic human neonates and adults [12], we hypothesized that newborn mice would be able to increase the megakaryocyte number, but not size, in response to increased platelet demand.

Overall, our murine studies further supported our hypothesis that there are biological differences in megakaryocytopoiesis between neonates and adults, which are evident under normal as well as pathological conditions. First, we confirmed that the hematologic system of a healthy newborn mouse closely resembles a mid-secondtrimester human fetus, with the liver being the primary site of hematopoiesis while also exhibiting some hematopoietic activity in the bone marrow $[19,20]$. Furthermore, these initial studies confirmed that megakaryocytopoiesis in the newborn mouse shares many features of megakaryocytopoiesis in human neonates, with neonatal

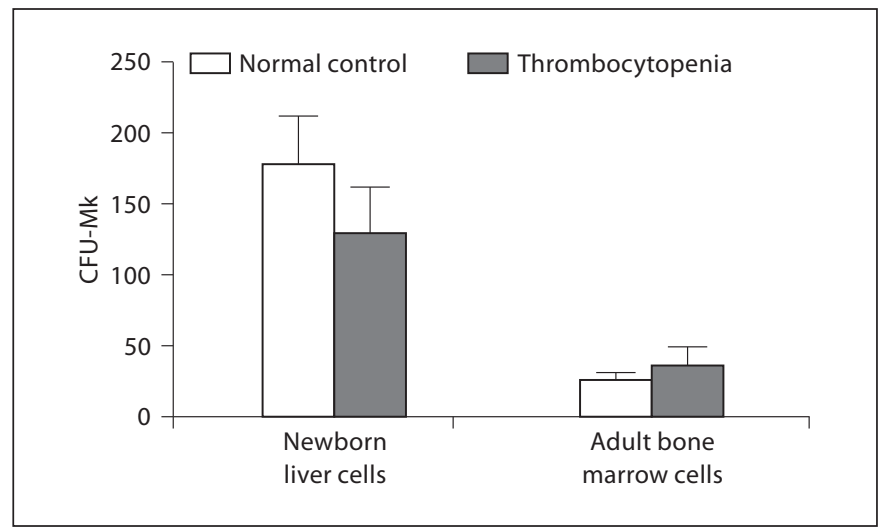

Fig. 4. Megakaryocyte colonies (CFU-Mk) generated from newborn liver and adult bone marrow. Murine newborn liver cells (Liv) generated significantly more megakaryocyte colonies than adult bone marrow cells in culture (mean megakaryocyte colonies per $1 \times 10^{5}$ cells plated: $181.1 \pm 32.8$ for newborn liver versus $26.5 \pm 4.3$ for adult bone marrow, $\mathrm{p}<0.001)$. There were no significant differences between thrombocytopenic and nonthrombocytopenic age-matched controls in regard to colony counts. Data are presented as mean \pm SEM.

megakaryocytes in both species being substantially smaller than their adult counterparts. These observations supported the theory that platelet counts in the newborn are maintained primarily by the high proliferative rate of megakaryocyte progenitors, and also confirmed the suitability of the murine model to study developmental differences in megakaryocytopoiesis.

The response of adult mice to thrombocytopenia was consistent with the findings of previous studies in animal models and in humans with consumptive thrombocytopenia, and was characterized by an overall compensatory increase in megakaryocyte mass. Most previous studies evaluating megakaryocy topoiesis in adult animal models of experimental thrombocytopenia reported an early and rapid increase in megakaryocyte volume, which reached a peak between days 3 and $4[10,21,22]$, followed by increased megakaryocyte numbers between days 4 and 10 after the onset of thrombocytopenia [10]. We chose 7 days of thrombocytopenia because after 7 days we expected to see compensatory changes in both megakaryocyte size and number.

Interestingly, the most significant changes in our model were observed in the spleen. The importance of the spleen as a megakaryocytopoietic organ in adult mice treated with various pharmacologic agents [23], with leukemic or myeloproliferative states $[24,25]$, and also with 
acute thrombocytopenia induced by platelet antiserum [26] has been demonstrated by several studies. More recently, the role of the spleen in the post bone marrow transplant setting, where it seems to be the organ of first response, has also been highlighted [27-29]. Furthermore, studies of posttransplantation megakaryocytopoiesis have consistently shown that the largest megakaryocytes are produced in the spleen and at the earliest posttransplantation stages [27-29]. Our findings indicate that this is also true in response to immune-mediated thrombocytopenia in adult mice. Newborn mice, in contrast, significantly increased the concentration of megakaryocytes in the spleen, but not the megakaryocyte volume, in response to fetal thrombocytopenia. These findings are consistent with our prior observations in human neonates with thrombocytopenia, who also exhibited increased megakaryocyte numbers without a corresponding increase in megakaryocyte size [12].

Translating splenic findings from mouse models to humans has been difficult because the contribution of the spleen to human megakaryocytopoiesis remains unclear. In adult humans, G-CSF has been shown to cause splenomegaly, thought to be due to induction of extramedullary hematopoiesis [30, 31]. In human fetuses, the spleen does not normally function as a site of granulocytopoiesis or erythropoiesis at mid-gestation [32], but its contribution to normal or to stress fetal megakaryocytopoiesis has never been studied. Nevertheless, we believe that the finding that murine neonatal splenic megakaryocytes significantly increase in number, but not in volume, in response to thrombocytopenia supports the hypothesis that our observations in human neonates represent true developmental differences.

We also elected to express megakaryocyte size as volume (in a manner similar to previous studies by Harker $[10,11])$ because even small changes in megakaryocyte diameter translate into large changes in megakaryocyte volume, and because the volume, rather than the diameter of each megakaryocyte, determines the number and size of platelets that it produces. When applying this concept, however, it is important to recognize that the process of sample fixation induces tissue shrinkage, so that our measurements do not represent actual in vivo sizes. Nevertheless, since all samples were processed in a similar manner, this method allows for comparisons between groups.

Similar to our previous report in human neonates and adults [12], our murine studies suggest that neonates have a limited ability to increase megakaryocyte size in response to thrombocytopenia. The reasons underlying the lack of increase in megakaryocyte size in newborn mice are unclear. Previous transplant studies by our group evaluating the phenotype of neonatal megakaryocytes in the adult microenvironment demonstrated that the developmental differences between neonatal and adult megakaryocytes are due both to cell-intrinsic and to microenvironmental differences [29]. Among the cell-intrinsic differences, we recently reported that the response of human megakaryocytes to Tpo is different at various stages of development. Specifically, under identical culture conditions, Tpo potently stimulated the maturation and polyploidization of adult megakaryocytes, while it inhibited the polyploidization of neonatal megakaryocytes [33]. Since megakaryocyte ploidy and size are closely correlated, it is tempting to hypothesize that these different responses to Tpo contribute to the observed differences in megakaryocyte size between neonates and adults. In regard to the fetal versus adult hematopoietic microenvironment, developmental differences might exist in the expression levels of factors stimulating or suppressing megakaryocyte maturation (i.e. IL-6 [34], IL-11 [35], vascular endothelial growth factor [36], platelet factor 4 [37]), or of chemokines that have been proven critical for megakaryocyte maturation, such as stromal-derived factor and/or fibroblast growth factor 4 [38]. Prior studies have also shown that thrombocytopenic neonates have lower serum Tpo concentrations than adults with similar mechanisms and degrees of thrombocytopenia $[39,40]$. These findings have led to the hypothesis that neonates do not upregulate Tpo production to the same degree as adults, which could presumably also contribute to the blunted response to thrombocytopenia observed in neonates.

We also recognize that the fetal thrombocytopenia induced in our model was only moderate. It could therefore be hypothesized that the lack of response in newborn pups was associated with the moderate severity of the thrombocytopenia [41]. However, the doses and routes of administration of the antibody were carefully titrated to generate similar degrees of thrombocytopenia in newborn and adult mice, so that most adult mice in our study also had moderate thrombocytopenia. Furthermore, previous studies have shown that platelet levels of approximately $40 \%$ of normal induce enlargement of megakaryocytes [21], a finding that was present in adult but not newborn mice.

Several mechanisms have been proposed to explain the decrease in platelet production sometimes observed in immune thrombocytopenia, including inhibition of megakaryocyte proliferation or maturation induced by 
the antibodies [26, 42-45]. Our findings do not support any of these mechanisms in association with MWReg30 because an increase in megakaryocyte mass was observed in the adult mice in response to the administration of this antibody, and there was no evidence of suppressed megakaryocytopoiesis in any adult organ. While a developmental limitation in the ability of neonates to increase their megakaryocyte volume seems to be the most likely explanation for the neonatal findings, we recognize that developmental differences in antigen concentration on platelets and megakaryocytes, and differences in the immune system leading to variable rates of antibody binding and clearance might have played a role [46]. In addition, the possibility that antiplatelet antibodies might have different effects on megakaryocytes depending on developmental stages cannot be excluded.
In conclusion, our study provides evidence that neonatal mice, similarly to human neonates, do not increase megakaryocyte volume in response to immune thrombocytopenia to the same degree as adults with the same type of thrombocytopenia. These observations further support the theory that there are substantial differences between neonatal and adult megakaryocytopoiesis, and might explain the predisposition of neonates to develop prolonged and severe thrombocytopenia.

\section{Acknowledgments}

This work was partially supported by NIH grant HL069990 (M.S.-V.) and a Fellowship from the German Academic Exchange Service, DAAD (H.S.).

\section{References}

1 Castle V, Andrew M, Kelton J, Giron D, Johnston M, Carter C: Frequency and mechanism of neonatal thrombocytopenia. J Pediatr 1986;108:749-755.

2 Mehta P, Vasa R, Neumann L, Karpatkin M: Thrombocytopenia in the high-risk infant. Pediatr 1980;97:791-794.

$\checkmark 3$ Burstein SA, Harker LA: Control of platelet production. Clin Haematol 1983;12:3-22.

4 Hegyi E, Nakazawa M, Debili N, Navarro S, Katz A, Breton-Gorius J, Vainchenker W: Developmental changes in human megakaryocyte ploidy. Exp Hematol 1991;19:8794.

5 Allen Graeve JL, de Alarcon PA: Megakaryocytopoiesis in the human fetus. Arch Dis Child 1989;64:481-484.

6 de Alarcon PA, Graeve JL: Analysis of megakaryocyte ploidy in fetal bone marrow biopsies using a new adaptation of the Feulgen technique to measure DNA content and estimate megakaryocyte ploidy from biopsy specimens. Pediatr Res 1996;39:166-170.

$\checkmark 7$ Mattia G, Vulcano F, Milazzo L, Barca A, Macioce G, Giampaolo A, Hassan HJ: Different ploidy levels of megakaryocytes generated from peripheral or cord blood CD34+ cells are correlated with different levels of platelet release. Blood 2002;99:888-897.

$>8$ Zauli G, Valvassori L, Capitani S: Presence and characteristics of circulating megakaryocyte progenitor cells in human fetal blood. Blood 1993;81:385-390.

-9 Sola MC, Du Y, Hutson AD, Christensen RD: Dose-response relationship of megakaryocyte progenitors from the bone marrow of thrombocytopenic and non-thrombocytopenic neonates to recombinant thrombopoietin. Br J Haematol 2000;110:449-453.
10 Harker LA: Kinetics of thrombopoiesis. Clin Invest 1968;47:458-465.

11 Harker LA: Thrombokinetics in idiopathic thrombocytopenic purpura. Br J Haematol 1970;19:95-104

12 Sola-Visner MC, Christensen RD, Hutson AD, Rimsza LM: Megakaryocyte size and concentration in the bone marrow of thrombocytopenic and nonthrombocytopenic neonates. Pediatr Res 2007;61:479-484.

-13 Oyaizu N, Yasumizu R, Miyama-Inaba M, Nomura S, Yoshida H, Miyawaki S, Shibata Y, Mitsuoka S, Yasunaga K, Morii S, et al: (NZW x BXSB)F1 mouse. A new animal model of idiopathic thrombocytopenic purpura. J Exp Med 1988;167:2017-2022.

-14 Teeling JL, Jansen-Hendriks T, Kuijpers TW, de Haas M, van de Winkel JG, Hack CE, Bleeker WK: Therapeutic efficacy of intravenous immunoglobulin preparations depends on the immunoglobulin G dimers: studies in experimental immune thrombocytopenia. Blood 2001;98:1095-1099.

15 Crow AR, Song S, Semple JW, Freedman J, Lazarus AH: IVIg inhibits reticuloendothelial system function and ameliorates murine passive-immune thrombocytopenia independent of anti-idiotype reactivity. $\mathrm{Br} \mathrm{J} \mathrm{Hae}-$ matol 2001;115:679-686.

16 Sola MC, Rimsza LM: Mechanisms underlying thrombocytopenia in the neonatal intensive care unit. Acta Paediatr Suppl 2002;91: 66-73.

17 Clapp DW, Baley JE, Gerson SL: Gestational age-dependent changes in circulating hematopoietic stem cells in newborn infants. J Lab Clin Med 1989;113:422-427.
18 Enzan H, Takahashi H, Kawakami M, Yamashita S, Ohkita T, Yamamoto M: Light and electron microscopic observations of hepatic hematopoiesis of human fetuses. II. Megakaryocytopoiesis. Acta Pathol Jpn 1980;30:937-954

19 Forestier F, Daffos F, Catherine N, Renard M, Andreux JP: Developmental hematopoiesis in normal human fetal blood. Blood 1991;77:2360-2363.

20 Pahal GS, Jauniaux E, Kinnon C, Thrasher AJ, Rodeck CH: Normal development of human fetal hematopoiesis between eight and seventeen weeks' gestation. Am J Obstet Gynecol 2000;183:1029-1034.

-21 Ebbe S, Stohlman F Jr, Overcash J, Donovan J, Howard D: Megakaryocyte size in thrombocytopenic and normal rats. Blood 1968;32: 383-392.

22 Odell TT, Murphy JR, Jackson CW: Stimulation of megakaryocytopoiesis by acute thrombocytopenia in rats. Blood 1976;48: 765-775.

23 Shiotsu Y, Akinaga S, Yamashita K, Murakata C, Tamaoki T, Ishida Y, Kuriya S, Teramura $\mathrm{M}$, Mizoguchi $\mathrm{H}$ : In vitro and in vivo effects of KT6352, a derivative of indolocarbazole compounds, on murine megakaryocytopoiesis. Exp Hematol 1998;26:1195-

24 Hawley RG, Fong AZ, Burns BF, Hawley TS: Transplantable myeloproliferative disease induced in mice by an interleukin 6 retrovirus. J Exp Med 1992;176:1149-1163.

25 Ritchie KA, Aprikyan AA, Bowen-Pope DF, Norby-Slycord CJ, Conyers S, Bartelmez S, Sitnicka EH, Hickstein DD: The Tel-PDGFRbeta fusion gene produces a chronic myeloproliferative syndrome in transgenic mice. Leukemia 1999;13:1790-1803. 
26 Levin J, Levin FC, Metcalf D: The effects of acute thrombocytopenia on megakaryocyte-CFC and granulocyte-macrophageCFC in mice: studies of bone marrow and spleen. Blood 1980;56:274-283.

-27 Li XM, Hu Z, Sola-Visner M, Hensel S, Garner R, Zafar AB, Wingard JR, Jorgensen ML, Fisher RC, Scott EW, Slayton WB: Sites and kinetics of donor thrombopoiesis following transplantation of whole bone marrow and progenitor subsets. Exp Hematol 2007;35: 1567-1579.

-28 Slayton WB, Georgelas A, Pierce LJ, Elenitoba-Johnson KS, Perry SS, Marx M, Spangrude GJ: The spleen is a major site of megakaryopoiesis following transplantation of murine hematopoietic stem cells. Blood 2002;100:3975-3982.

-29 Slayton WB, Wainman DA, Li XM, Hu Z, Jotwani A, Cogle CR, Walker D, Fisher RC, Wingard JR, Scott EW, Sola MC: Developmental differences in megakaryocyte maturation are determined by the microenvironment. Stem Cells 2005;23:1400-1408.

$\checkmark 30$ Brown SL, Dale DC: Spontaneous splenic rupture following administration of granulocyte colony-stimulating factor (G-CSF): occurrence in an allogeneic donor of peripheral blood stem cells. Biol Blood Marrow Transplant 1997;3:341-343.

>31 Becker PS, Wagle M, Matous S, Swanson RS, Pihan G, Lowry PA, Stewart FM, Heard SO: Spontaneous splenic rupture following administration of granulocyte colony-stimulating factor (G-CSF): occurrence in an allogeneic donor of peripheral blood stem cells. Biol Blood Marrow Transplant 1997;3: 45-49.

>32 Calhoun DA, Li Y, Braylan RC, Christensen RD: Assessment of the contribution of the spleen to granulocytopoiesis and erythropoiesis of the mid-gestation human fetus. Early Hum Dev 1996;46:217-227.
33 Pastos KM, Slayton WB, Rimsza LM, Young L, Sola-Visner MC: Differential effects of recombinant thrombopoietin and bone marrow stromal-conditioned media on neonatal versus adult megakaryocytes. Blood 2006; 108:3360-3362.

34 Wickenhauser C, Thiele J, Lorenzen J, Schmitz B, Frimpong S, Schramm K, Neumann I, Zankovich R, Fischer R: Polycythemia vera megakaryocytes but not megakaryocytes from normal controls and patients with smokers polyglobuly spontaneously express IL-6 and IL-6R and secrete IL-6. Leukemia 1999;13:327-334.

35 Suen Y, Chang M, Lee SM, Buzby JS, Cairo MS: Regulation of interleukin-11 protein and mRNA expression in neonatal and adult fibroblasts and endothelial cells. Blood 1994 84:4125-4134.

36 Bobik R, Hong Y, Breier G, Martin JF, Erusalimsky JD: Thrombopoietin stimulates VEGF release from c-Mpl-expressing cell lines and haematopoietic progenitors. FEBS Lett 1998;423:10-14.

\$37 Ravid K, Beeler DL, Rabin MS, Ruley HE, Rosenberg RD: Selective targeting of gene products with the megakaryocyte platelet factor 4 promoter. Proc Natl Acad Sci USA 1991;88:1521-1525.

38 Avecilla ST, Hattori K, Heissig B, Tejada R, Liao F, Shido K, Jin DK, Dias S, Zhang F, Hartman TE, Hackett NR, Crystal RG, Witte L, Hicklin DJ, Bohlen P, Eaton D, Lyden D, de Sauvage F, Rafii S: Chemokine-mediated interaction of hematopoietic progenitors with the bone marrow vascular niche is required for thrombopoiesis. Nat Med 2004; 10:64-71.

-39 Murray NA, Watts TL, Roberts IA: Endogenous thrombopoietin levels and effect of recombinant human thrombopoietin on megakaryocyte precursors in term and preterm babies. Pediatr Res 1998;43:148-151.
40 Sola MC, Calhoun DA, Hutson AD, Christensen RD: Plasma thrombopoietin concentrations in thrombocytopenic and nonthrombocytopenic patients in a neonatal intensive care unit. Br J Haematol 1999;104: 90-92.

41 Corash L, Chen HY, Levin J, Baker G, Lu H, Mok Y: Regulation of thrombopoiesis: effects of the degree of thrombocytopenia on megakaryocyte ploidy and platelet volume. Blood 1987;70:177-185.

42 Abgrall JF, Berthou C, Sensebe L, Le Niger C, Escoffre M: Decreased in vitro megakaryocyte colony formation in chronic idiopathic thrombocytopenic purpura. Br J Haematol 1993;85:803-804.

43 Abgrall JF, el-Kassar N, Berthou C, Renard I, Cauvin JM, Le Pailleur A, Autrand C, Sensebe L, Guern G, Zilliken P, et al: In vitro megakaryocyte colony formation in patients with idiopathic thrombocytopenic purpura: differences between acute and chronic ITP. Int J Cell Cloning 1992;10:28-32.

44 de Alarcon PA, Mazur EM, Schmieder JA: In vitro megakaryocytopoiesis in children with acute idiopathic thrombocytopenic purpura. Am J Pediatr Hematol Oncol 1987;9:212218.

45 Sugiyama H, Yagita M, Takahashi T, Nakamura $\mathrm{K}$, Iho $\mathrm{S}$, Hoshino $\mathrm{T}$, Imura $\mathrm{H}$ : Megakaryocytopoiesis in idiopathic thrombocytopenic purpura. Nippon Ketsueki Gakkai Zasshi 1987;50:119-128.

46 Kühne T, Ryan G, Blanchette V, Semple JW, Hornstein A, Mody M, Chang W, McWhirter L, Freedman J: Platelet-surface glycoproteins in healthy and preeclamptic mothers and their newborn infants. Pediatr Res 1996; 40:876-880. 